\title{
Putting Risk IN ITs PROPER Place
}

\author{
LOUIS EECKHOUDT \\ HARRIS SCHLESINGER
}

CESIFO WORKING PAPER NO. 1462

CATEGORY 10: EMPIRICAL AND TheORETICAL MethodS

MAY 2005

An electronic version of the paper may be downloaded

- from the SSRN website:

http://SSRN.com/abstract $=713282$

- from the CESifo website:

www.CESifo.de 


\title{
Putting Risk in ITs PRoPer Place
}

\begin{abstract}
This paper examines preferences towards particular classes of lottery pairs. We show how concepts such as prudence and temperance can be fully characterized by a preference relation over these lotteries. If preferences are defined in an expected-utility framework with differentiable utility, the direction of preference for a particular class of lottery pairs is equivalent to signing the nth derivative of the utility function. What makes our characterization appealing is its simplicity, which seems particularly amenable to experimentation.
\end{abstract}

JEL Code: D81

Keywords: properness, prudence, risk apportionment, risk aversion, stochastic dominance, temperance, utility premium.

\author{
Louis Eeckhoudt \\ Catholic Faculties of Mons University \\ (FUCAM) \\ Chaussée de Binche 151 \\ Mons 7000 \\ Belgium \\ louis.eeckhoudt@fucam.ac.be
}

\author{
Harris Schlesinger \\ Department of Finance \\ University of Alabama \\ Tuscaloosa AL 35487-0224 \\ USA \\ hschlesi@cba.ua.edu
}

This paper was partly written while both authors were visiting at the IDEI, University of Toulouse. Financial support from the French Federation of Insurance Companies (FFSA) is gratefully acknowledged. We thank seminar participants at the EGRIE meeting in Zurich, CORE, DELTA, the University of Bologna, the University of Pennsylvania and Rice University for many useful comments on a draft version of this paper. Detailed comments from Georges Dionne, Neil Doherty, Christian Gollier, Miles Kimball, Achim Wambach, Claudio Zoli and three referees were especially helpful. 


\section{Putting Risk in its Proper Place}

The concept of risk aversion has long been a cornerstone for modern research on the economics of risk. Ask several economists to define what it means for an individual to be risk averse and you are likely to get several different answers. Some, assuming an expectedutility framework, will say that the second derivative of the von Neumann-Morgenstern utility function $u$ is concave or, assuming differentiability, that $u^{\prime \prime}<0$. Others might define risk aversion in a more general setting, equating it to an aversion to mean-preserving spreads, as defined by Michael Rothschild and Joseph E. Stiglitz (1970). It is not likely that one would define risk aversion via some behavioral consequence, such as the propensity to purchase full insurance at an actuarially-fair price.

Although somewhat newer, the concept of "prudence" and its relationship to precautionary savings also has become a common and accepted assumption. ${ }^{1}$ Ask someone to define what it means for the individual to be "prudent" and they might say that marginal utility is convex, $u^{\prime \prime \prime}>0$, but they also might define prudence via behavioral characteristics. For example, Christian Gollier (2001 p. 236), defines an agent as prudent "if adding an uninsurable zero-mean risk to his future wealth raises his optimal saving." In other words, unlike the case with risk aversion, prudence is often defined via an optimizing type of behavior, rather than some type of more primitive trait. ${ }^{2}$

More recently, some new concepts have entered the literature such as "temperance" $\left(u^{i v}<0\right)$ and "edginess" $\left(u^{v}>0\right)$, which arise as necessary and/or sufficient conditions for various behavioral results. ${ }^{3}$ But what exactly are these concepts and what do they imply 
about one's preference towards risk?

Within an expected-utility framework, in contrast to ordinal utility, the sign of every derivative of the von Neumann-Morgenstern utility function $u$ has some economic meaning. In this paper, we derive a class of lottery pairs such that the direction of preference between these lotteries is equivalent to signing the $n^{t h}$ derivative of utility. The lotteries themselves are particularly simple, involving equal likelihoods for all outcomes, which would seem particularly amenable to experimentation. Moreover, since the signs of the first $n$ derivatives of utility are well-known to coincide with a preference for $n^{\text {th }}$-degree stochastic dominance, our lottery preferences also are compatible with stochastic-dominance preference.

Although our results are interpreted in this paper in a context of preferences towards risk, it turns out that they can be given other economic interpretations. The most direct application is likely in the area of income distribution, where concepts such as "inequality aversion" and "aversion to downside inequality" have been employed for some time. See for example the papers by Anthony B. Atkinson (1970) and by Anthony F. Shorrocks and James E. Foster (1987). Our results are also relevant to the literatures on the competitive firm under price uncertainty, labor supply, auctions and portfolio choice. ${ }^{4}$

Justifying the sign of higher order derivatives can often meet with skepticism. For example, Miles Kimball's (1993) "standard risk aversion," which has been shown to have many implications, is becoming a more common assumption in the literature. This condition requires $u^{i v} \leq\left(u^{\prime \prime \prime}\right)^{2} / u^{\prime \prime}<0$, yet the weaker condition of temperance, $u^{i v}<0$, typically is met with skepticism.

Our goal in this paper is to provide a set of natural conditions regarding behavior towards risk, in the form of a preference relation between pairs of simple lotteries. In particular, we start out by assuming that an individual dislikes two things: a certain reduction in wealth and adding a zero-mean independent noise random variable to the 
distribution of wealth. We define "prudence," for example, as a type of preference for disaggregation of these two untoward events. We define "temperance" in a similar manner, except we replace the certain reduction in wealth with a second independent zero-mean risk. Temperance is defined as preference for disaggregating these two independent risks. We then extend and generalize these concepts by nesting the above types of lotteries. By defining our set of preferences over lotteries, we provide relatively simple behavioral characterizations of the mathematical assumption that the derivatives of the utility function are alternating in sign: $\operatorname{sgn} u^{(n)}=\operatorname{sgn}(-1)^{n+1}$ for all positive integers $n$. This describes the class of so-called "mixed risk averse" utility functions, as defined by Jordi Caballé and Alexey Pomansky (1996), a class which includes most all of the commonly used von Neumann-Morgenstern utility functions. ${ }^{5}$

Our "tool" in deriving these results is the utility premium, measuring the degree of "pain" involved in adding risk. Although this measure actually predates more formal analyses of behavior under risk, as pioneered by Kenneth J. Arrow (1965) and John W. Pratt (1964), it has been largely ignored in the literature. ${ }^{6}$

The following section defines preferences over lotteries that correspond to prudence and temperance. We then generalize these lottery preferences to particular types of rational behavior, which we term "risk apportionment," and show how they are equivalent to signing derivatives of the utility function within an expected-utility framework. Finally, we discuss how our results fit in with several other concepts in the literature.

\section{Prudence and Temperance}

We consider two basic "building blocks" for our analysis. The first is a sure reduction in wealth of arbitrary size $k, k>0$. The second is the addition of a zero-mean random variable $\widetilde{\varepsilon}$, where $\widetilde{\varepsilon}$ is assumed to be non-degenerate and to be independent of any other 
random variables that may be present in an individual's initial wealth allocation. We let $x$ denote the individual's initial wealth, where $x$ is arbitrary in size, $x>0$. We assume $x$ is non-random for simplification, although initial wealth may be random so long as a random $\widetilde{x}$ is statistically independent of $\widetilde{\varepsilon}$. We also assume that random wealth is constructed in such a way as to have its support contained within a range of well-defined preferences. ${ }^{7}$

In order to avoid mathematical nuances, we only consider weak preference relations in this paper. ${ }^{8}$ For any two lotteries $A$ and $B$, we use the notation $B \succcurlyeq A$ to denote the individual's preference relation "lottery $B$ is at least as good as lottery $A . "$

We define preferences as monotonic if $x \succcurlyeq x-k \forall x$ and $\forall k$. We define preferences to be risk averse if $x \succcurlyeq x+\widetilde{\varepsilon} \forall x$ and $\forall \widetilde{\varepsilon}$. While not necessary for our definition of risk aversion, one usually thinks of monotonicity as jointly holding. However, it is certainly possible to desire as little wealth as possible and still be risk averse.

To keep the notation consistent, define the "lottery" $B_{1}$ as $B_{1}=[0,0]$ and the "lottery" $A_{1}$ as $A_{1}=[-k,-k]$, where all simple lotteries are assumed to have an equal probability for each outcome. Similarly, define the "lotteries" $B_{2}$ and $A_{2}$ as $B_{2}=[0,0]$ and $A_{2}=[\widetilde{\varepsilon}, \widetilde{\varepsilon}]$. Thus, we can define preferences as being monotone if $B_{1} \succcurlyeq A_{1}$ and as being risk averse if $B_{2} \succcurlyeq A_{2}$ for all initial wealth levels $x$ and for all $k$ and all $\widetilde{\varepsilon}$.

\section{$1.1 \quad$ Prudence}

Prudence is defined within expected-utility confines by Kimball (1990), who shows it is analogous to a precautionary-savings motive in a particular type of consumption/savings model. We define prudence in this paper as a type of natural preference over simple lotteries. Later, we will show how this definition coincides with Kimball's characterization. ${ }^{9}$

Definition 1: An individual is said to be prudent if the lottery $B_{3}=[-k ; \widetilde{\varepsilon}]$ is preferred to the lottery $A_{3}=[0, \widetilde{\varepsilon}-k]$, where all outcomes of the lotteries have equal probability, for 
all initial wealth levels $x$ and for all $k$ and all $\widetilde{\varepsilon}$.

Thus, prudence shows a type of preference for disaggregation of a sure loss of size $k$ and the addition of a zero-mean random variable $\widetilde{\varepsilon}$. If preferences are also monotonic and risk averse, the individual prefers to receive one of the two "harms" for certain, with the only uncertainty being about which one is received, as opposed to a 50-50 chance of receiving both "harms" simultaneously or receiving neither. Borrowing terminology from Kimball (1993), the above property implies that $-k$ and $\widetilde{\varepsilon}$ are "mutually aggravating" for all initial wealth levels $x$ and for all $k$ and all $\widetilde{\varepsilon}$.

We also can interpret prudence as type of "location preference" for one of the harms within a lottery. In particular, consider the lottery $[0 ;-k]$. Now suppose the individual is told that she must accept a zero-mean random variable $\widetilde{\varepsilon}$, but she only must receive it in tandem with one of the two lottery outcomes. The prudent individual will always prefer to attach the risk $\widetilde{\varepsilon}$ to the better outcome 0 , rather than to the outcome $-k$. This characterization already has been noted by Louis Eeckhoudt, et al. (1995) and essentially follows from the earlier work of Hanson and Menezes (1971). In a sense, we are more willing to accept an extra risk when wealth is higher, rather than when wealth is lower. Indeed, this logic helps to explain why someone opts for a higher savings when second period income is risky in a two-period model. The resulting higher wealth in the second period helps one to cope with the additional risk, exactly as in Kimball (1990), who uses prudence as equivalent to a precautionary demand for savings. ${ }^{10}$

\subsection{Temperance}

We now add a second zero-mean random variable. Let $\widetilde{\varepsilon}_{1}$ and $\widetilde{\varepsilon}_{2}$ denote these two zeromean random variables. We assume that $\widetilde{\varepsilon}_{1}$ and $\widetilde{\varepsilon}_{2}$ are statistically independent of each other as well as independent from other random variables that might be owned by the 
individual.

Definition 2: An individual is said to be temperate if the lottery $B_{4}=\left[\widetilde{\varepsilon}_{1}\right.$; $\left.\widetilde{\varepsilon}_{2}\right]$ is preferred to the lottery $A_{4}=\left[0 ; \widetilde{\varepsilon}_{1}+\widetilde{\varepsilon}_{2}\right]$, where all outcomes of the lotteries have equal probability, for all initial wealth levels $x$ and for all $\widetilde{\varepsilon}_{1}$ and $\widetilde{\varepsilon}_{2}$.

Thus, temperance shows a type of preference for disaggregation of the two independent zero-mean random variables. Temperance, as defined above, also can be interpreted as a type of location preference for adding a second independent zero-mean risk to the lottery $\left[0 ; \widetilde{\varepsilon}_{2}\right]$. Suppose the individual must accept a second zero-mean random variable $\widetilde{\varepsilon}_{1}$, but she only must receive it in tandem with one of the two lottery outcomes. The temperate individual will always prefer to attach the second risk $\widetilde{\varepsilon}_{1}$ to the better outcome 0 , rather than to the worse outcome $\widetilde{\varepsilon}_{2}$. This means that we must dislike the risk $\widetilde{\varepsilon}_{1}$ more in the presence of $\widetilde{\varepsilon}_{2}$. The risks $\widetilde{\varepsilon}_{1}$ and $\widetilde{\varepsilon}_{2}$ are "mutually aggravating" in the terminology of Kimball (1993).

\section{Generalizing Prudence and Temperance}

Let $\left\{\widetilde{\varepsilon}_{i}\right\}$ denote an indexed set of zero-mean non-degenerate random variables, $i=1,2,3, \ldots$, where we assume that the $\widetilde{\varepsilon}_{i}$ are all mutually independent and that the $\widetilde{\varepsilon}_{i}$ are also independent of any existing risks in an individual's wealth. We assume throughout this paper that all lotteries have equally-likely outcomes. We now generalize the concepts of prudence and of temperance as a type of preference for disaggregation of the "harms" $-k$ and $\widetilde{\varepsilon}_{i}$.

\subsection{Risk Apportionment}

If $C$ denotes a lottery, we can think of this lottery as essentially defining a random variable. In particular, the lottery $C$ generates a probability distribution over wealth outcomes. As a matter of notation, if $\widetilde{y}$ denotes a random variable that is independent of $C$, we let $\widetilde{y}+C$ 
denote the sum of the random variables. ${ }^{11}$

As a matter of terminology, we will say that preferences satisfy risk apportionment of order 1 if they are monotonic, i.e. if $B_{1} \succcurlyeq A_{1}$. If preferences are risk averse, so that $B_{2} \succcurlyeq A_{2}$, we say that preferences satisfy risk apportionment of order 2. In a similar manner we define risk apportionment of order 3 as the equivalence of prudence, $B_{3} \succcurlyeq A_{3}$, and risk apportionment of order 4 as the equivalent of temperance, $B_{4} \succcurlyeq A_{4}$. To define risk apportionment of higher orders, we proceed iteratively. ${ }^{12}$

\subsubsection{Risk Apportionment of orders 5 and 6}

We define risk apportionment of order 5, RA-5, as follows:

Definition 3: Assume that outcomes of the lotteries below all have equal probability. Preferences are said to satisfy risk apportionment of order 5 if, for all initial wealth levels $x$ and for all $k, \widetilde{\varepsilon}_{1}, \widetilde{\varepsilon}_{2}$ and $\widetilde{\varepsilon}_{3}$, the lottery $B_{5}=\left[0+A_{3} ; \widetilde{\varepsilon}_{2}+B_{3}\right]$ is preferred to the lottery $A_{5}=\left[0+B_{3} ; \widetilde{\varepsilon}_{2}+A_{3}\right]$. Preferences satisfy risk apportionment of order 6 if the lottery $B_{6}=\left[0+A_{4} ; \widetilde{\varepsilon}_{3}+B_{4}\right]$ is preferred to the lottery $A_{6}=\left[0+B_{4} ; \widetilde{\varepsilon}_{3}+A_{4}\right]$.

This definition does not require risk apportionment of lower orders. But if we have risk aversion, then we know that $0 \succcurlyeq \widetilde{\varepsilon}_{2}$, and if we have prudence, then we know that $B_{3} \succcurlyeq A_{3}$. We can thus interpret risk apportionment of order 5 as a preference location for adding the risk $\widetilde{\varepsilon}_{2}$ : Given that we must add $\widetilde{\varepsilon}_{2}$ to one of the outcomes in the lottery $\left[B_{3} ; A_{3}\right]$, we would prefer to add it to the better outcome $B_{3}$. Similarly, if we have risk aversion, then we know that $0 \succcurlyeq \widetilde{\varepsilon}_{3}$, and if we have temperance, then we know that $B_{4} \succcurlyeq A_{4}$. We also can interpret risk apportionment of order 6 as a preference location for adding the risk $\widetilde{\varepsilon}_{3}$ : Given that we must add $\widetilde{\varepsilon}_{3}$ to one of the outcomes in the simple lottery $\left[B_{4} ; A_{4}\right]$, we would prefer to add it to the better outcome $B_{4}$. We illustrate $A_{6}$ and $B_{6}$ and how they relate to risk apportionment of order 6 in Figure 1. Risk apportionment of order 5 is easily 
illustrated in a similar manner.

Figure 1: Risk Apportionment of Order 6, $B_{6} \succcurlyeq A_{6}$
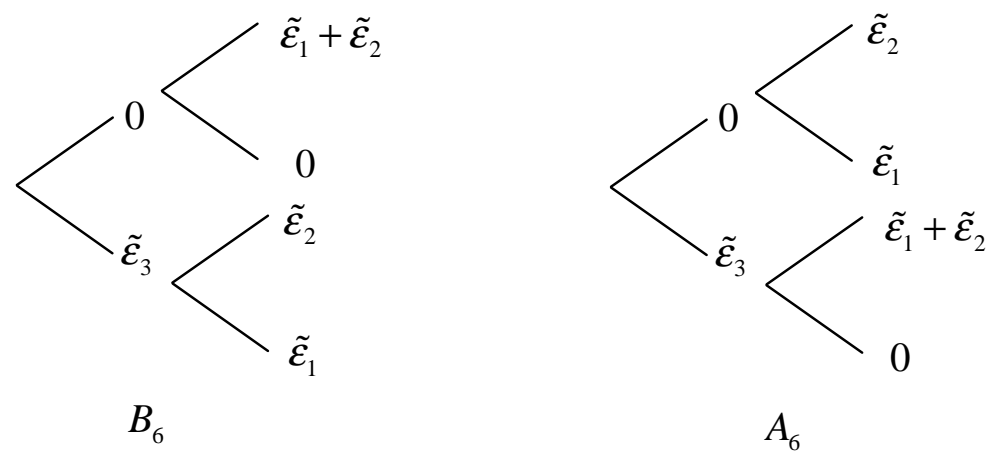

Assuming reduction of compound lotteries, it is trivial to verify that $k, \widetilde{\varepsilon}_{1}$ and $\widetilde{\varepsilon}_{2}$ are all interchangeable wherever they appear in lotteries $A_{5}$ and $B_{5}$. Likewise, we can replace $-k$ with $\widetilde{\varepsilon}_{3}$ in any formulation of $A_{5}$ and $B_{5}$ to obtain $A_{6}$ and $B_{6}$ respectively.

\subsection{Risk apportionment of order $n$}

Given the definitions $B_{1}=B_{2}=[0], A_{1}=[-k]$ and $A_{2}=\left[\widetilde{\varepsilon}_{1}\right]$ we can iterate on the definitions above to define risk apportionment of order $n$. First, we define the appropriate lotteries:

Definition 4: Assume that the outcomes of all lotteries $A_{i}$ and $B_{i}$ as listed here have equal probabilities. Further assume that $k>0$ and that all $\widetilde{\varepsilon}_{i}$ are mutually independent with a zero mean. Let Int $(y)$ denote the greatest-integer function, i.e. the greatest integer not exceeding the real number $y$. Then for each $n \geq 3$ we define the following lotteries:

$$
A_{n}=\left[0+B_{n-2} ; \widetilde{\varepsilon}_{I n t(n / 2)}+A_{n-2}\right] .
$$




$$
B_{n}=\left[0+A_{n-2} ; \widetilde{\varepsilon}_{\operatorname{Int}(n / 2)}+B_{n-2}\right] .
$$

We now can define risk apportionment for the general case:

Definition 5: Preferences are said to satisfy risk apportionment order $n$ if, for the lotteries $A_{n}$ and $B_{n}$ as defined above, the individual always prefers $B_{n}: B_{n} \succcurlyeq A_{n}$.

For example, suppose that we start from the lottery $\left[0, \widetilde{\varepsilon}_{4}\right]$, and are told that we must add $A_{6}$ to one outcome and add $B_{6}$ to the other outcome, where $A_{6}$ and $B_{6}$ are as illustrated in Figure 1. Risk apportionment of order 8 would indicate a preference for attaching the more preferred lottery $B_{6}$ to the less preferred outcome $\widetilde{\varepsilon}_{4}$.

\section{Utility Equivalence}

In this section, we show how risk apportionment coincides with very particular conditions on the utility function, $u$, within an expected-utility framework. We assume that $u$ is continuously differentiable over the domain of wealth. The approach we use here is quite a direct use of the utility premium. Lottery $B$ is preferred to lottery $A$ if and only if it causes less pain when added to any initial wealth level $x$. Since all of our risks are assumed to be mutually independent as well as independent of any risks inherent in initial wealth, it would not matter if we allowed $\tilde{x}$ to be random. For the sake of simplicity, we only consider nonrandom $x$ values below. ${ }^{13}$

\subsection{Some Properties of the Utility Premium}

Let $\left\{\tilde{\varepsilon}_{i}\right\}$ denote an indexed set of mutually-independent zero-mean random variables. We assume that each $\tilde{\varepsilon}_{i}$ is a non-degenerate random variable, i.e. $\tilde{\varepsilon}_{i}$ has a non-zero variance. 
We define the utility premium for the risk $\tilde{\varepsilon}_{1}$ at wealth level $x$ as

$$
w_{1}(x) \equiv E u\left(x+\tilde{\varepsilon}_{1}\right)-u(x) .
$$

Note that we define the utility premium as the gain in expected utility from adding the zero-mean risk $\tilde{\varepsilon}_{1}$ to wealth $x .{ }^{14}$

By our definition, the utility premium is negative if and only if preferences are risk averse,

$$
w_{1}(x) \equiv E u\left(x+\tilde{\varepsilon}_{1}\right)-u(x) \leq 0 \quad \forall x \text { if and only if } u^{\prime \prime} \leq 0 .
$$

Similarly, it follows trivially from Jensen's inequality that

$$
w_{1}^{\prime}(x) \equiv E u^{\prime}\left(x+\tilde{\varepsilon}_{1}\right)-u^{\prime}(x) \geq 0 \quad \forall x \text { if and only if } u^{\prime \prime \prime} \geq 0
$$

and

$$
w_{1}^{\prime \prime}(x) \equiv E u^{\prime \prime}\left(x+\tilde{\varepsilon}_{1}\right)-u^{\prime \prime}(x) \leq 0 \quad \forall x \text { if and only if } u^{i v} \leq 0
$$

Thus we see that $w_{1}$ as defined here is increasing and concave whenever $u^{\prime \prime \prime} \geq 0$ and $u^{i v} \leq 0$. In other words, $w_{1}$ exhibits the properties of a risk-averse utility function on its own. Of course these properties coincide with prudence and temperance in the expectedutility literature. We next show that they are equivalent to our definitions of prudence and temperance from the previous section. 


\subsection{Prudence and Utility}

Condition (3) is equivalent to our definition of prudence, since we can allow our sure reduction in wealth, $-k$, to be arbitrarily small. Note that from (1) - (3) above, it follows that prudence, $u^{\prime \prime \prime} \geq 0$, is equivalent to each of the following:

(i) Adding $\tilde{\varepsilon}_{1}$ to a higher wealth level is "less painful" (i.e. the absolute size of the utility premium is decreasing in $x$ ).

(ii) Adding $\tilde{\varepsilon}_{1}$ to wealth increases the expected marginal utility.

Kimball (1990) noted both of these properties and used them to model precautionary savings. In his set-up, an income risk is added in the second of two periods. This induces the individual to shift some nonrandom wealth to the second period (via more savings in the first period) in order to help mitigate the pain.

From $(i)$ above and inequality (4), if we also have prudence, we can interpret $u^{i v} \leq 0$ as implying that the pain from adding $\tilde{\varepsilon}_{1}$ to wealth decreases as one gets wealthier, but it decreases at a decreasing rate. We next show that $u^{i v} \leq 0$ is equivalent to our definition of temperance.

\subsection{Temperance and Utility}

Let $\tilde{\varepsilon}_{2}$ be a zero-mean risk that is independent of $\tilde{\varepsilon}_{1}$. We iterate on the above procedure for defining the utility premium, and define $w_{2}$ as the utility premium for $w_{1}$ (regardless of whether or not $w_{1}$ is increasing or concave):

$$
w_{2}(x) \equiv E w_{1}\left(x+\tilde{\varepsilon}_{2}\right)-w_{1}(x)
$$

If $w_{1}$ is concave, then $w_{2}$ will be everywhere negative. From (4), this implies that

$$
w_{2}(x) \equiv E w_{1}\left(x+\tilde{\varepsilon}_{2}\right)-w_{1}(x) \leq 0 \quad \forall x \text { if and only if } u^{i v} \leq 0
$$


Using only Jensen's inequality, in a manner similar to $w_{1}$, we can continue to find

$$
w_{2}^{\prime}(x) \equiv E w_{1}^{\prime}\left(x+\tilde{\varepsilon}_{2}\right)-w_{1}^{\prime}(x) \geq 0 \quad \forall x \text { if and only if } u^{v} \geq 0
$$

and

$$
w_{2}^{\prime \prime}(x) \equiv E w_{1}^{\prime \prime}\left(x+\tilde{\varepsilon}_{2}\right)-w_{1}^{\prime \prime}(x) \leq 0 \quad \forall x \text { if and only if } u^{v i} \leq 0 .
$$

To see that $u^{i v} \leq 0$ is equivalent to temperance, use (1) to expand (6). It follows that $u^{i v} \leq 0$ is equivalent to

$$
\left[E u\left(x+\tilde{\varepsilon}_{1}+\tilde{\varepsilon}_{2}\right)-E u\left(x+\tilde{\varepsilon}_{2}\right)\right]-\left[E u\left(x+\tilde{\varepsilon}_{1}\right)-u(x)\right] \leq 0
$$

or equivalently

$$
\frac{1}{2}\left[E u\left(x+\tilde{\varepsilon}_{1}\right)+E u\left(x+\tilde{\varepsilon}_{2}\right)\right] \geq \frac{1}{2}\left[u(x)+E u\left(x+\tilde{\varepsilon}_{1}+\tilde{\varepsilon}_{2}\right)\right] .
$$

Inequality (10) is clearly an expected-utility equivalent to our lottery-preference definition of temperance (Definition 2).

\subsection{Risk Apportionment of Orders 5 and 6}

We can use $w_{2}$ to show that risk apportionment of order 5 (RA-5) is equivalent to $u^{v} \geq 0$ by once again noting that our Definition 3 allows for the sure reduction in wealth $-k$ to be arbitrarily small. Equivalently, we can write (7) as

$$
\left[E w_{1}\left(x+\tilde{\varepsilon}_{2}\right)-w_{1}(x)\right]-\left[E w_{1}\left(x-k+\tilde{\varepsilon}_{2}\right)-w_{1}(x-k)\right] \geq 0 .
$$


Expanding $w_{1}$ in (11) and rearranging shows that it is equivalent to the lottery-preference definition for RA-5 (Definition 3).

To show that risk apportionment of order 6 is equivalent to $u^{v i} \leq 0$, we need to iterate once again on the utility premium and define

$$
w_{3}(x) \equiv E w_{2}\left(x+\tilde{\varepsilon}_{3}\right)-w_{2}(x)
$$

where $\tilde{\varepsilon}_{3}$ is a zero-mean risk independent of $\tilde{\varepsilon}_{2}$ and $\tilde{\varepsilon}_{2}$. Similar to our analysis above, it follows from Jensen's inequality that $w_{3} \leq 0$ if and only if $w_{2}$ is concave, which we have already proven is equivalent to $u^{v i} \leq 0$. Expanding the inequality $w_{3} \leq 0$ by using (1) and (5), it is straightforward to show that $u^{v i} \leq 0$ is equivalent to our lottery-preference characterization of RA-6 in Definition 4.

\subsection{Risk Apportionment of Order $\mathbf{n}$}

One can continue on in this manner by demonstrating that $w_{3}^{\prime} \geq 0$ is equivalent to $u^{v i i} \geq 0$, as well as equivalent to our definition of RA-7. To obtain the equivalence of $u^{\text {viii }} \leq 0$ and RA-8, we need to define $w_{4}$ as the utility premium of $w_{3}$. We can iterate in this manner for any $n \geq 3$ :

(i) For $n$ even, we define $w_{n / 2}(x) \equiv E w_{(n / 2)-1}\left(x+\tilde{\varepsilon}_{(n / 2)-1}\right)-w_{(n / 2)-1}(x)$. Expanding this expression we can show that $u^{(n)} \leq 0$ iff $w_{n / 2}(x) \leq 0$ iff RA- $n$ holds.

(ii) For $n$ odd, we use the equivalence of $u^{(n)} \geq 0$ and $w_{(n-1) / 2}^{\prime}(x) \geq 0$ and demonstrate how this non-negative derivative is equivalent to the lottery preference for RA- $n$.

This leads to the following main result, showing how risk apportionment relates to derivatives of the utility function.

Theorem: In an expected-utility framework with differentiable u, risk apportionment 
of order $n$ is equivalent to the condition $\operatorname{sgn} u^{(n)}=\operatorname{sgn}(-1)^{n+1}$.

\section{Related Concepts}

Many papers have looked at the implications of signing higher order derivatives of utility in an expected-utility framework, but very few have pinned down the meaning of these signs in and of themselves. The advantage of risk apportionment lies mainly in its simplicity. The fact that it is defined over lottery preferences also makes it applicable outside of an expected-utility framework. Thus, concepts like "prudence" and "temperance" can be generalized and embedded into other frameworks for choice under risk. In this section, we examine how our results in this paper relate to some of the extant literature.

\subsection{Higher Order Effects}

Within expected-utility models, growth rates and elasticities are typically second-order effects because they relate the effect of changes in an exogenous variable on a first-order condition. ${ }^{15}$ Decreasing absolute risk aversion (DARA) is a third-order property because it has to do with changes in risk aversion (a second-order property). Prudence is also a third-order property, since it relates the effect of risk on a first-order condition. However, DARA is a stronger condition than simply assuming prudence, in particular, requiring that $u^{\prime \prime \prime} \geq\left(u^{\prime \prime}\right)^{2} / u^{\prime}$

In a sense, we can think of prudence itself, $u^{\prime \prime \prime}>0$, as a pure third-order effect. A straightforward interpretation of inequality (3) is that the "pain" of adding a risk $\widetilde{\varepsilon}$ decreases as one gets wealthier. On the other hand, decreasing risk aversion implies that one's willingness to pay to remove a risk is decreasing as one gets wealthier. But this "willingness to pay" in a sense contains too much information, since it must relate the

changing level of "pain" to the marginal valuation of paying a dollar to remove this "pain." 16 
We can take this argument to higher orders. Consider the interaction of two risks, $\widetilde{\varepsilon}_{1}$ and $\widetilde{\varepsilon}_{2}$, which is a fourth-order effect. Many authors have formulations similar to our lottery defining prudence, in Definition 2. For example, Pratt and Richard Zeckhauser (1987) define preferences as being "proper" if $\left[\widetilde{\varepsilon}_{1} ; \widetilde{\varepsilon}_{2}\right] \succeq\left[0 ; \widetilde{\varepsilon}_{1}+\widetilde{\varepsilon}_{2}\right]$ not for all zero-mean risks $\widetilde{\varepsilon}_{1}$ and $\widetilde{\varepsilon}_{2}$, but rather risks that are undesirable to the individual: each reduces expected utility of the individual when added to wealth. ${ }^{17}$ Gollier and Pratt (1996), in defining the very useful concept of risk vulnerability, essentially look at this same lottery preference, but where one of the risks, say $\widetilde{\varepsilon}_{2}$, is restricted to the set of risks that are undesirable for all risk-averse individuals, which implies $\widetilde{\varepsilon}_{2}$ has a non-positive mean. Kimball, defines standard risk aversion in much the same manner, but where $\widetilde{\varepsilon}_{2}$, is restricted to the set of risks that increase marginal utility. Naturally, temperance is a necessary condition for both of these formulations, since they both include zero-mean risks $\widetilde{\varepsilon}_{1}$ and $\widetilde{\varepsilon}_{2}$ as a special case. By allowing for non-zero means, all of these formulations include effects of other orders, and do not isolate the pure fourth-order effect of temperance. ${ }^{18}$

\subsection{Stochastic Dominance}

One obvious related area is that of stochastic dominance. Stochastic dominance establishes a partial ordering of probability distributions for which it is well known that wealth distribution $F$ dominates wealth distribution $G$ in the sense of $n^{t h}$-order stochastic dominance if and only if everyone with a utility function $u$ for which $\operatorname{sgn} u^{(j)}=\operatorname{sgn}(-1)^{j+1}$ for $j=1,2, \ldots, n$ prefers $F$ to $G .{ }^{19}$ Such a utility function is said to satisfy stochasticdominance preference of order $n$. Hence, from our Theorem it follows that preferences satisfy stochastic-dominance preference of order $n$ if and only if they satisfy risk apportionment of order $j$ for all $j=1,2, \ldots, n$.

Steinar Ekern (1981) limits the distributions $F$ and $G$ to those for which $F$ dominates 
$G$ by stochastic dominance of order $n$, but not for any orders less than $n$. In this case, he says that $G$ has more $n^{\text {th }}$ degree risk than $F$. He then shows how this condition is equivalent to saying that every individual with $\operatorname{sgn} u^{(n)}=\operatorname{sgn}(-1)^{n+1}$ would prefer $F$ to $G$. He labels such an individual as " $n^{\text {th }}$ degree risk averse." Obviously then, it follows from our Theorem that Ekern's $n^{\text {th }}$ degree risk aversion is equivalent to preferences satisfying risk apportionment of order $n$.

Given the comments above, it is clear that others have already characterized the signs of the derivatives of the utility function. What makes risk apportionment so appealing is its simplicity. For instance, consider RA-4 (temperance, or equivalently $u^{i v} \leq 0$ ). For those readers familiar with stochastic dominance, think of describing distributions where there is stochastic dominance of order 4 , but not of orders 1,2 or 3 . Of course this is possible, but it is hardly simple. Compare this to the simplicity of assuming the lottery $\left[\widetilde{\varepsilon}_{1}, \widetilde{\varepsilon}_{2}\right]$ is preferred to $\left[0, \widetilde{\varepsilon}_{1}+\widetilde{\varepsilon}_{2}\right]$.

This simplicity of our lottery design with equal probabilities, also lends itself well to experimental design. While framing contexts and situationalism will surely still play a role, the complexity of understanding the lottery itself is not an issue, especially for RA-n where $n$ is not too large. Thus, a concept like temperance seems quite plausible. On the other hand, our definition of temperance $(n=4)$ requires that $\left[\widetilde{\varepsilon}_{1}, \widetilde{\varepsilon}_{2}\right]$ be preferred to $\left[0, \widetilde{\varepsilon}_{1}+\widetilde{\varepsilon}_{2}\right]$ for all independent $\widetilde{\varepsilon}_{1}$ and $\widetilde{\varepsilon}_{2}$. This must hold not only if $\widetilde{\varepsilon}_{1}$ and $\widetilde{\varepsilon}_{2}$ are identically distributed, but even if, say, $\widetilde{\varepsilon}_{1}$ has a very large variance and the variance of $\widetilde{\varepsilon}_{2}$ is extremely small. In such a setting, behaviorists might have us believe that many individuals will be lured by the "certainty" of the first outcome in the lottery $\left[0, \widetilde{\varepsilon}_{1}+\widetilde{\varepsilon}_{2}\right]$, and thus prefer it to $\left[\widetilde{\varepsilon}_{1}, \widetilde{\varepsilon}_{2}\right]$. 


\subsection{Aversion to Outer Risk}

Perhaps the closest approach to our own is that of Menezes and X. Henry Wang (2005), who relate the property of temperance to the notion of outer risk. In their model, they formally show how $\left[\widetilde{\varepsilon}_{1} ; \widetilde{\varepsilon}_{2}\right] \succeq\left[0 ; \widetilde{\varepsilon}_{1}+\widetilde{\varepsilon}_{2}\right]$ implies fourth-order stochastic dominance of the corresponding lottery distribution functions, thus equating this lottery preference to $u^{i v} \leq 0 .{ }^{20}$ We can generalize their notion of outer risk as follows.

In general, we cannot order $\widetilde{\varepsilon}_{1}$ and $\widetilde{\varepsilon}_{2}$, with respect to preferences. But we can construct the chain $0 \succeq \widetilde{\varepsilon}_{i} \succeq \widetilde{\varepsilon}_{1}+\widetilde{\varepsilon}_{2}$, where $i=1$ or $i=2$. To this end, consider $\left\{\widetilde{\varepsilon}_{1}, \widetilde{\varepsilon}_{2}\right\}$ as the "inner risks" and $\left\{0, \widetilde{\varepsilon}_{1}+\widetilde{\varepsilon}_{2}\right\}$ as the "outer risks." Our definition of temperance (Definition 2) thus states that a 50-50 gamble between the inner risks is preferred to one between the outer risks.

We can also use Menezes' and Wang's concept of inner and outer risks to describe

higher-order risk apportionment. For example, consider the simple lottery $\left[0, \widetilde{\varepsilon}_{1}, \widetilde{\varepsilon}_{2}, \widetilde{\varepsilon}_{1}+\widetilde{\varepsilon}_{2}\right]$, where all four outcomes have equal probability. If we must attach a sure loss of $k>0$ to either the two inner risks or to the two outer risks, RA-5 is equivalent to always preferring to attach $-k$ to the two inner risks. RA-6 can be defined in a similar manner, where we replace the sure loss $-k$ with an independent third risk $\widetilde{\varepsilon}_{3}$. We can achieve all higher orders of risk apportionment by simple iteration on these results.

\section{Concluding Remarks}

For a long time, risk aversion has played a key role in the theory of choice under uncertainty; not only within expected-utility (EU) models, but also within other decision-theoretic frameworks. It was recognized quite early on, that the sign of $u^{\prime \prime \prime}$ played a key role within EU, but it was not until Kimball (1990) that this role was formalized into the concept of 
"prudence." Since this formalization, models of consumption and savings decisions have received a new focus and made many advancements. Outside of EU, these advances have come mostly from trying to mimic either the consequences that follow within EU, or to mimic some of the parametric nuances of properties such as DARA and prudence. The role of signing higher order derivatives, such as assuming "temperance" or "edginess," is only recently receiving more interest in the literature.

By considering simple lottery preferences, we are able to provide a characterization of these properties based only on underlying preferences. In particular, we define such properties by our lottery preference, and then we show how these definitions are equivalent to signing the $n^{\text {th }}$ derivative within EU models. Since our definitions are not confined to EU, they are applicable within other choice-theoretic frameworks as well. The types of lotteries we examine are rather simple, especially for fairly low values of $n$, making them quite amenable to experiments about individual behavior towards risk. 


\section{Notes}

${ }^{1}$ The term "prudence" was coined by Miles Kimball (1990), although the importance of the third derivative of utility in determining a precautionary savings demand was noted much earlier by Hayne E. Leland (1968) and Agnar Sandmo (1970).

${ }^{2}$ One notable exception is the paper by Carmen F. Menezes, C. Geiss and John Tressler (1980), who describe "aversion to downside risk" and relate it to the sign of $u^{\prime \prime \prime}$.

${ }^{3}$ We use the notations $u^{(4)}(x)$ and $u^{i v}(x)$ interchangeably to denote the fourth derivative of $u, \frac{d^{4} u(x)}{d x^{4}}$. Similarly, we denote the $n^{\text {th }}$ derivative by $u^{(n)}$ as well as by a Roman-numeral superscript.

${ }^{4} \mathrm{~A}$ summary of results relating stochastic dominance, and hence our lottery preference, to income distribution can be found in Patrick Moyes (1999). The other economic applications mentioned above are scattered throughout the literature, but a good overview of many of them can be found in the book by Elmar Wolfstetter (1999).

${ }^{5}$ This property is labeled "complete properness" by John W. Pratt and Richard Zeckhauser (1987). This class of utility functions also was examined independently by Patrick L. Brocket and Linda L. Golden (1987).

${ }^{6}$ One notable exception is the paper by D. L. Hanson and Menezes (1971), who more than 30 years ago had made this exact same observation. To the best of our knowledge, the first direct look at the utility premium was the work of Milton Friedman and Leonard J. Savage (1948).

${ }^{7}$ For instance, if preferences are defined only over positive levels of final wealth, we assume throughout the paper that all changes to wealth, be it by subtracting a fixed wealth or adding a random wealth term, are chosen so as to preserve wealth to be positive.

${ }^{8}$ Strict-preference analogs follow, but require significantly more-complex modelling, with little extra in the way of economic insight. 
${ }^{9}$ John P. Bigelow and Menezes (1995) essentially show that our lottery preference as defined below is equivalent to $u^{\prime \prime \prime} \geq 0$. Our main distinction here is to use this lottery preference relation as the definition of prudence.

${ }^{10}$ Equivalently, we can start from the lottery $[0 ; \widetilde{\varepsilon}]$ and define prudence as a preference for attaching the harm $-k$ to the outcome 0 , rather than to the outcome $\widetilde{\varepsilon}$.

${ }^{11}$ More formally, if $F_{y}$ and $F_{c}$ denote the (marginal) distribution functions of random variables $\widetilde{y}$ and $C$ respectively, then the distribution over the sum of these random variables $\widetilde{y}+C$ is given by the convolution of these distribution functions, $F_{y} * F_{c}$.

${ }^{12}$ We do not particularly like introducing new terminology, but one overarching goal is to have a generalized concept that can be extended to various orders, much along the lines of stochastic dominance. By apportioning harms within a lottery, we wish to mitigate their detrimental effects. Hence the terminology "risk apportionment." For orders 1 and 2 , this makes less sense, but we include the terminology to have consistency in our general results. Obviously risk apportionment of order 3 is already well known as "prudence" and "temperance" in the extant sense is equivalent in our definition to risk apportionment of order 4 .

${ }^{13}$ For a random $\widetilde{x}$, we can simply replace utility $u$ with the derived utility function $\widehat{u}(y)=E u(y+\widetilde{x})$, as defined by David Nachman (1982). It follows trivially that the signs of the $n^{\text {th }}$ derivatives of $u$ and $\widehat{u}$ with respect to $y$ will all be the same.

${ }^{14}$ This is the negative of how the utility premium is often defined, in the scant literature on the topic. However, one very notable exception is Friedman and Savage (1948). Defining it in this manner helps to facilitate our discussions that follow.

${ }^{15}$ For example, absolute risk aversion and relative risk aversion are respectively the decay rate and elasticity of changes in marginal utility with respect to increases in wealth. Note, however, that if preferences are not required to be "smooth," such as allowing non- 
differentiability of $u$ at some wealth levels, risk aversion might also be a first-order effect, as pointed out by Uzi Segal and Avia Spivak (1990).

${ }^{16}$ For example, the reader can easily verify that, under the common assumption of constant absolute risk aversion (CARA), the level of "pain" associated with adding the risk $\widetilde{\varepsilon}$ is actually decreasing in wealth, whereas the willingness to pay to remove a unit of "pain" is increasing in wealth. Of course, under CARA, these two effects exactly offset one another.

${ }^{17}$ Actually, this lottery formulation is not presented by Pratt and Zeckhauser (1997) themselves, but rather by a reformulation of their result by Kimball (2003).

${ }^{18}$ These same arguments have been taken up to the fifth-order recently by Fatma LajeriChaherli (2004), who also provides a nice summary of the fourth-order concepts of properness, risk vulnerability and standard risk aversion. Her fifth-order effect of "standard prudence" relates to precautionary savings in the presence of a background risk.

${ }^{19}$ See, for example, Johnathan E. Ingersoll (1987).

${ }^{20}$ They show equivalence for their more general formulation of increased outer risk. The lottery they consider as an illustration is the same as the one we present here, with $\widetilde{\varepsilon}_{2}$ being restricted as $\widetilde{\varepsilon}_{2}=[-1,+1]$. 


\section{References}

[1] Arrow, Kenneth .J. Yrjo Jahnsson Lecture Notes. Helsinki: Yrjo Jahnsson Foundation, 1965. Reprinted in: Arrow, K.J. Essays in the Theory of Risk Bearing. Chicago: Markum Publishing Company, 1971.

[2] Atkinson, Anthony B. " On the Measurement of Inequality." Journal of Economic Theory 2, 1970, pp. 244-63.

[3] Bigelow, John P. and Menezes, Carmen F. "Outside Risk Aversion and the Comparative Statics of Increasing Risk in Quasi-Linear Decision Models." International Economic Review, August 1995, 36(3), pp. 643-73.

[4] Brockett, Patrick L. and Golden, Linda L. "A Class of Utility Functions Containing All The Common Utility Functions." Management Science, August 1987, 33(8), pp. 955-964

[5] Caballé, Jordi and Pomansky, Alexey. "Mixed Risk Aversion." Journal of Economic Theory 71, 1995, pp. 485-513.

[6] Eeckhoudt, Louis; Gollier, Christian and Schneider, Thierry. "Risk-Aversion, Prudence and Temperance: A Unified Approach." Economics Letters 48, 1995, pp. 331336.

[7] Eeckhoudt, Louis; Gollier, Christian and Schlesinger, Harris. "Changes in Background Risk and Risk Taking Behavior." Econometrica 64, 1996, pp. 683-689.

[8] Ekern, Steinar. "Increasing $N^{\text {th }}$ Degree Risk." Economics Letters 6, 1980, pp. 329-333.

[9] Friedman, Milton and Savage, Leonard J. "The Utility Analysis of Choices Involving Risk." Journal of Political Economy 56, 1948, pp. 279-304. 
[10] Gollier, Christian The Economics of Risk and Time. Cambridge: MIT Press, 2001.

[11] Gollier, Christian, and Pratt, John W. "Risk Vulnerability and the Tempering Effect of Background Risk." Econometrica, 64, 1996, 1109-1124.

[12] Hanson, D.L. and Menezes, Carmen F. "On a Neglected Aspect of the Theory of Risk Aversion." Western Economic Journal 9, 1971, pp. 211-217.

[13] Ingersoll, Jonathan E. Theory of Financial Decision Making. New Jersey: Rowman \& Littlefield, 1987.

[14] Kimball, Miles S. "Precautionary Savings in the Small and in the Large." Econometrica 58, 1990, pp. 53-73.

[15] Kimball, Miles S. "Precautionary Motives for Holding Assets." in The New Palgrave Dictionary of Money and Finance. P. Newman, M. Milgate, and J. Falwell, eds. London: MacMillan, 1992.

[16] Kimball, Miles S. "Standard Risk Aversion.” Econometrica 61, 1993, pp. 589-611.

[17] Lajeri-Chaherli, Fatma. "Proper Prudence, Standard Prudence and Precautionary Vulnerability." Economics Letters 82, 2004, pp. 29-34.

[18] Leland, Hayne E. "Saving and Uncertainty: The Precautionary Demand for Saving." Quarterly Journal of Economics 82, 1968, pp. 465-73.

[19] Menezes, Carmen F.; Geiss, C. and Tressler, John. "Increasing Downside Risk." American Economic Review 70, 1980, pp. 921-932.

[20] Menezes, Carmen F. and Wang, X. Henry. "Increasing Outer Risk." Journal of Mathematical Economics, 2005, forthcoming. 
[21] Moyes, Patrick. "Stochastic Dominance and the Lorenz Curve," in Jacques Silber, ed., Handbook of Income Inequality Measurement. Boston: Kluwer Academic Publishers, 1999, pp. 199-222.

[22] Nachman, David. "Preservation of 'More Risk Averse' under Expectations." Journal of Economic Theory 28, 1982, pp. 361-368

[23] Pratt, John W. "Risk Aversion in the Small and in the Large." Econometrica 32, 1964, pp. $122-136$.

[24] Pratt, John W. and Zeckhauser, Richard. "Proper Risk Aversion." Econometrica, 55, 1987, pp. 143-154.

[25] Rothschild, Michael and Stiglitz, Joseph E. "Increasing Risk: I. A Definition." Journal of Economic Theory 2, 1970, pp. 225-243.

[26] Sandmo, Agnar. "The Effect of Uncertainty on Saving Decisions." Review of Economic Studies 37, 1970, pp. 353-60.

[27] Segal, Uzi and Spivak, Avia. "First Order versus Second Order Risk Aversion." Journal of Economic Theory 51, 1990, pp. 111-125.

[28] Shorrocks, Anthony F., and Foster, James E. "Transfer Sensitive Inequality Measures." Review of Economic Studies 54, 1987, pp. 485-97.

[29] Wolfstetter, Elmar. Topics in Microeconomics. Cambridge, UK: Cambridge University Press, 1999. 


\title{
CESifo Working Paper Series
}

\author{
(for full list see www.cesifo.de)
}

1397 Marko Köthenbürger, Panu Poutvaara and Paola Profeta, Why are More Redistributive Social Security Systems Smaller? A Median Voter Approach, February 2005

1398 Gabrielle Demange, Free Choice of Unfunded Systems: A First Assessment, February 2005

1399 Carlos Fonseca Marinheiro, Sustainability of Portuguese Fiscal Policy in Historical Perspective, February 2005

1400 Roel M. W. J. Beetsma and Koen Vermeylen, The Effect of Monetary Unification on Public Debt and its Real Return, February 2005

1401 Frank Asche, Petter Osmundsen and Maria Sandsmark, Is It All Oil?, February 2005

1402 Giacomo Corneo, Media Capture in a Democracy: The Role of Wealth Concentration, February 2005

1403 A. Lans Bovenberg and Thijs Knaap, Ageing, Funded Pensions and the Dutch Economy, February 2005

1404 Thiess Büttner, The Incentive Effect of Fiscal Equalization Transfers on Tax Policy, February 2005

1405 Luisa Fuster, Ayşe İmrohoroğlu and Selahattin İmrohoroğlu, Personal Security Accounts and Mandatory Annuitization in a Dynastic Framework, February 2005

1406 Peter Claeys, Policy Mix and Debt Sustainability: Evidence from Fiscal Policy Rules, February 2005

1407 James M. Malcomson, Supplier Discretion over Provision: Theory and an Application to Medical Care, February 2005

1408 Thorvaldur Gylfason, Interview with Assar Lindbeck, February 2005

1409 Christian Gollier, Some Aspects of the Economics of Catastrophe Risk Insurance, February 2005

1410 Gebhard Kirchgässner, The Weak Rationality Principle in Economics, February 2005

1411 Carlos José Fonseca Marinheiro, Has the Stability and Growth Pact Stabilised? Evidence from a Panel of 12 European Countries and Some Implications for the Reform of the Pact, February 2005

1412 Petter Osmundsen, Frank Asche, Bård Misund and Klaus Mohn, Valuation of International Oil Companies -The RoACE Era, February 2005 
1413 Gil S. Epstein and Shmuel Nitzan, Lobbying and Compromise, February 2005

1414 Marcel F. M. Canoy, Jan C. van Ours and Frederick van der Ploeg, The Economics of Books, February 2005

1415 Eric A. Hanushek and Ludger Wößmann, Does Educational Tracking Affect Performance and Inequality? Differences-in-Differences Evidence across Countries, February 2005

1416 George Kapetanios and M. Hashem Pesaran, Alternative Approaches to Estimation and Inference in Large Multifactor Panels: Small Sample Results with an Application to Modelling of Asset Returns, February 2005

1417 Samuel Mühlemann, Jürg Schweri, Rainer Winkelmann and Stefan C. Wolter, A Structural Model of Demand for Apprentices. February 2005

1418 Giorgio Brunello and Lorenzo Rocco, Educational Standards in Private and Public Schools, February 2005

1419 Alex Bryson, Lorenzo Cappellari and Claudio Lucifora, Why so Unhappy? The Effects of Unionisation on Job Satisfaction, March 2005

1420 Annalisa Luporini, Relative Performance Evaluation in a Multi-Plant Firm, March 2005

1421 Giorgio Bellettini and Carlotta Berti Ceroni, When the Union Hurts the Workers: A Positive Analysis of Immigration Policy, March 2005

1422 Pieter Gautier, Michael Svarer and Coen Teulings, Marriage and the City, March 2005

1423 Ingrid Ott and Stephen J. Turnovsky, Excludable and Non-Excludable Public Inputs: Consequences for Economic Growth, March 2005

1424 Frederick van der Ploeg, Back to Keynes?, March 2005

1425 Stephane Dees, Filippo di Mauro, M. Hashem Pesaran and L. Vanessa Smith, Exploring the International Linkages of the Euro Area: a Global VAR Analysis, March 2005

1426 Hans Pitlik, Friedrich Schneider and Harald Strotmann, Legislative Malapportionment and the Politicization of Germany's Intergovernmental Transfer System, March 2005

1427 Konstantinos Angelopoulos and Apostolis Philippopoulos, The Role of Government in Anti-Social Redistributive Activities, March 2005

1428 Ansgar Belke and Daniel Gros, Asymmetries in the Trans-Atlantic Monetary Policy Relationship: Does the ECB follow the Fed?, March 2005

1429 Sören Blomquist and Luca Micheletto, Optimal Redistributive Taxation when Government's and Agents' Preferences Differ, March 2005 
1430 Olof Åslund and Peter Fredriksson, Ethnic Enclaves and Welfare Cultures - QuasiExperimental Evidence, March 2005

1431 Paul De Grauwe, Roberto Dieci and Marianna Grimaldi, Fundamental and NonFundamental Equilibria in the Foreign Exchange Market. A Behavioural Finance Framework, March 2005

1432 Peter Egger, Stefan Gruber, Mario Larch and Michael Pfaffermayr, Knowledge-Capital Meets New Economic Geography, March 2005

1433 George Economides and Apostolis Philippopoulos, Should Green Governments Give Priority to Environmental Policies over Growth-Enhancing Policies?, March 2005

1434 George W. Evans and Seppo Honkapohja, An Interview with Thomas J. Sargent, March 2005

1435 Helge Berger and Volker Nitsch, Zooming Out: The Trade Effect of the Euro in Historical Perspective, March 2005

1436 Marc-Andreas Muendler, Rational Information Choice in Financial Market Equilibrium, March 2005

1437 Martin Kolmar and Volker Meier, Intra-Generational Externalities and InterGenerational Transfers, March 2005

1438 M. Hashem Pesaran and Takashi Yamagata, Testing Slope Homogeneity in Large Panels, March 2005

1439 Gjermund Nese and Odd Rune Straume, Industry Concentration and Strategic Trade Policy in Successive Oligopoly, April 2005

1440 Tomer Blumkin and Efraim Sadka, A Case for Taxing Education, April 2005

1441 John Whalley, Globalization and Values, April 2005

1442 Denise L. Mauzerall, Babar Sultan, Namsoug Kim and David F. Bradford, Charging $\mathrm{NO}_{x}$ Emitters for Health Damages: An Exploratory Analysis, April 2005

1443 Britta Hamburg, Mathias Hoffmann and Joachim Keller, Consumption, Wealth and Business Cycles in Germany, April 2005

1444 Kohei Daido and Hideshi Itoh, The Pygmalion Effect: An Agency Model with Reference Dependent Preferences, April 2005

1445 John Whalley, Rationality, Irrationality and Economic Cognition, April 2005

1446 Henning Bohn, The Sustainability of Fiscal Policy in the United States, April 2005

1447 Torben M. Andersen, Is there a Role for an Active Fiscal Stabilization Policy? April 2005 
1448 Hans Gersbach and Hans Haller, Bargaining Power and Equilibrium Consumption, April 2005

1449 Jerome L. Stein, The Transition Economies: A NATREX Evaluation of Research, April 2005

1450 Raymond Riezman, John Whalley and Shunming Zhang, Metrics Capturing the Degree to which Individual Economies are Globalized, April 2005

1451 Romain Ranciere, Aaron Tornell and Frank Westermann, Systemic Crises and Growth, April 2005

1452 Plutarchos Sakellaris and Focco W. Vijselaar, Capital Quality Improvement and the Sources of Growth in the Euro Area, April 2005

1453 Kevin Milligan and Michael Smart, Regional Grants as Pork Barrel Politics, April 2005

1454 Panu Poutvaara and Andreas Wagener, To Draft or not to Draft? Efficiency, Generational Incidence, and Political Economy of Military Conscription, April 2005

1455 Maurice Kugler and Hillel Rapoport, Skilled Emigration, Business Networks and Foreign Direct Investment, April 2005

1456 Yin-Wong Cheung and Eiji Fujii, Cross-Country Relative Price Volatility: Effects of Market Structure, April 2005

1457 Margarita Katsimi and Thomas Moutos, Inequality and Relative Reliance on Tariffs: Theory and Evidence, April 2005

1458 Monika Bütler, Olivia Huguenin and Federica Teppa, Why Forcing People to Save for Retirement may Backfire, April 2005

1459 Jos Jansen, The Effects of Disclosure Regulation of an Innovative Firm, April 2005

1460 Helge Bennmarker, Kenneth Carling and Bertil Holmlund, Do Benefit Hikes Damage Job Finding? Evidence from Swedish Unemployment Insurance Reforms, May 2005

1461 Steffen Huck, Kai A. Konrad and Wieland Müller, Merger without Cost Advantages, May 2005

1462 Louis Eeckhoudt and Harris Schlesinger, Putting Risk in its Proper Place, May 2005 